\title{
NEAR PERIPHERAL MOTION CONTRAST THRESHOLD PREDICTS OLDER DRIVERS' DRIVING SIMULATOR PERFORMANCE
}

\author{
Steven Henderson ${ }^{1}$, Sylvain Gagnon ${ }^{2}$, Charles Collin², \\ Ricardo Tabone ${ }^{2}$, Arne Stinchcombe ${ }^{2}$ \\ ${ }^{1}$ Transportation Safety Board of Canada \\ Hull, Quebec, Canada \\ ${ }^{2}$ School of Psychology, University of Ottawa \\ Ottawa, Ontario, Canada \\ E-mail: Steve.Henderson@tsb.gc.ca
}

\begin{abstract}
Summary: The method of descending limits assessed motion contrast thresholds of 11 young participants (17-28), and 21 older drivers (63-86) for 0.4 cycle/degree drifting Gabor stimuli at 15 degrees eccentricity. Peripheral motion contrast thresholds (PMCT) of younger participants $(M=-45.5 \mathrm{~dB}, S D=1.66$ $\mathrm{dB})$ and older participants $(M=-43.3 \mathrm{~dB}, S D=3.79 \mathrm{~dB})$ differed $(t(29)=2.295$, $p<.05$ (all $p$-values one-tailed)). Older drivers performed UFOV® tests and a high-fidelity driving simulation. Between independent variables, significant correlations were PMCT with UFOV2 $(r=.74, p<.001)$, PMCT with UFOV3 $(r$ $=.50, p<.01)$, PMCT with age $(r=.73, p<.001)$, UFOV2 with age $(r=.48, p<$ $.05)$, and UFOV3 with age $(r=.44, p<.05)$. Between vision and simulator measures, PMCT and UFOV2 significantly predicted rater's simulator score $(r=$ $.66, p<.001 ; r=.58, p<.01$ respectively), and simulator crashes $(r=.63, p<$ $.001 ; r=.72, p<.001$ respectively). Thus, PMCT and UFOV2 strongly predicted simulator performance. Partial correlations showed that: substantial association between PMCT and UFOV2 was not age-related; PMCT and UFOV2 tapped a common visual function; and PMCT assessed a component not captured by UFOV2. The descending limits procedure is as reliable and faster than forcedchoice. A practicable PMCT test that informs at-risk drivers about visual deficits may help them compensate effectively by learning voluntary scanning techniques and by otherwise modifying their driving techniques.
\end{abstract}

Collisions per mile increase after the age of 65, and more so after the age of 70 (HLDI, 2005; Li, Braver, \& Chen, 2003; Massie, Campbell \& Williams, 1995; NHTSA, 2001; Yanik, 1986). Of particular concern to road safety professionals and the General Accounting Office (2007) is that as baby boomers age into retirement, the age-related increase in accident risk will account for an ever-increasing proportion of overall road crashes. This issue can only be fairly addressed by identifying which visual functions critical for driving may be affected by normal aging, and then by developing effective and practicable assessment instruments and countermeasures.

Older drivers are most significantly overrepresented in motor vehicle crashes involving undetected crossing vehicles at intersections (Staplin et al, 1998). An age-related decline in visual motion detection may lead to some of these age-related attention or detection failure accidents (Henderson \& Donderi, 2005; Henderson, Gagnon, Bélanger, Tabone \& Collin, 2007). Henderson et al proposed that a decline in motion contrast sensitivity in the near periphery, analogous to the known decline in motion contrast sensitivity in central vision after 65 or 70 years of age (Sekuler \& Owsley, 1982), may impair some older drivers' visual orienting reflex 
toward encroaching objects. They reported that peripheral motion contrast thresholds (PMCT) correlated significantly with self-report accident risk questionnaires.

Driving simulators provide powerful, flexible means to manipulate driving scenarios in a controlled and safe environment, thereby taxing the visual functions that are important for mitigating traffic conflicts and safely negotiating the driving environment. Accordingly, we tested for a relation between older drivers' PMCT and their driving simulator performance. All UFOV ${ }^{\circledR}$ subtests (Ball et al, 2006) were also applied. We also tested for an age-related decline in PMCT across two age groups, and within a sample of older drivers. In addition, the method of descending limits we developed to assess PMCT required less than ten minutes, compared to the twenty minutes required by the previous two-alternative forced choice method (Henderson \& Donderi, 2005; Henderson et al, 2007).

\section{METHOD}

\section{Participants}

A younger driver sample of 11 student volunteer participants consisted of 3 men and 8 women between 17 and 28 years of age $(M=22.0, S D=4.14)$. The younger sample participated only in the PMCT assessment.

Initially, 28 older drivers participated in the study. However, 5 participants did not finish the testing due to simulator adaptation syndrome, and simulator performance data for 2 participants were lost. The initial older driver sample consisted of 23 men and 5 women between 63 and 86 years of age $(M=70.1, S D=4.99)$, and the final sample of 21 older drivers consisted of 17 men and 4 women between 63 and 82 years of age $(M=69.0, S D=4.20)$. Gender distributions within the samples precluded testing for gender effects.

All participants had at least 5 years of driving experience, all reported good mental and physical health with no history of neurological, psychiatric or substance abuse problems, and all were tested with their normal visual correction. All were residents of the Ottawa area and were paid 20 dollars for their participation.

\section{Vision Measures}

Peripheral motion contrast threshold. PMCT was determined for 0.4 cycles per degree Gabor stimuli (a vertical sine wave grating drifted centripetally at 13.75 degrees/sec within a Gaussian window) presented at fifteen degrees eccentricity, within a raised cosine temporal window of 1.5 seconds duration, preceded and followed by a 0.5 second blank interval. Gratings were presented on two CRT monitors $65 \mathrm{~cm}$ distant from the head fixation point. The stimuli were generated using MATLAB software on an IBM PC running Windows XP. Stimulus contrast was recorded in decibel units $(\mathrm{dB})$, which is $20 * \log ($ Michelson contrast).

The method of descending limits procedure consisted of eight blocks of descending contrast trials. Blocks alternated by side, and a block began at well above threshold contrast. In the first four blocks, contrast decreased $2 \mathrm{~dB}$ between trials, and in the last four blocks, contrast 
decreased $1 \mathrm{~dB}$ between trials. During a single trial, a participant looked directly ahead at a lit LED fixation point, and then indicated if a Gabor stimulus had appeared. A block ended when no grating was reported. A trial was discarded before evaluation if the participant made an eye movement. Peripheral motion contrast thresholds $(\mathrm{dB})$ were averaged across the eight blocks for each participant. All participants were able to complete the PMCT procedure within 10 minutes.

Useful field of view. All UFOV® subtests of visual attention (speed of processing, divided attention, selective attention), which is known to be a valid and reliable test for predicting older drivers' crashes and at fault accidents (Ball et al, 2006), were administered to all participants.

\section{Driving Performance Measure}

A high fidelity STISIM driving simulator (Systems Technology Inc., Build 3.00.04) presented a virtual roadway environment on three wide screens using three NEC projectors to yield a field of view of 80 degrees. The simulator software allows the experimenter to design urban and suburban roadway environments including interactive vehicles on all lanes, buildings, traffic control devices, and pedestrians through advanced vehicle dynamics and image generation. The virtual environment is supplemented with realistic audio effects providing acceleration cues. The software was run on a Windows XP operating system and Intel x86 Model 15 Family computers with a processing speed of $2394 \mathrm{MHz}$ (four systems required).

Participants completed a 10-minute training session of increasing complexity followed by a 20minute evaluation course. The evaluation course was patterned after a standard on-road driving test in residential, highway, and commercial environments. Crashes and missed stops (ie., a participant failed to stop before an intersection, which includes overshoots by a few feet) were recorded by the STISIM drive software. The experimenter also assessed drivers' simulator performance (G2-rater) using the evaluation procedure employed by Bédard et al (2008).

\section{Statistical Analyses}

Pearson Product-Moment correlations, step-wise regressions, and associated tests of significance were calculated across age, visual function (PMCT, UFOV®), and driving simulator performance using SAS Version 9.1. Where appropriate, tests were directional (ie., one-tailed). A $p$-value of $<.05$ was considered statistically significant.

\section{RESULTS}

Between age groups, younger driver PMCT $(M=-45.5 \mathrm{~dB}, S D=1.66 \mathrm{~dB}, N=11)$ was significantly lower $(t(29)=2.295, p<.05)$ than older driver PMCT $(M=-43.3 \mathrm{~dB}, S D=3.79$ $\mathrm{dB}, N=21)$. Note also that the variance of the older group was more than 8 times higher than that of the younger group, which is consistent with other studies showing that performance variability increases with age (Landy,1992; Tsang,1997).

A significant effect of age on PMCT was also found within the older driver group, as shown in Figure 1. 
The regression equation of Age on PMCT (shown in Figure 1) is PMCT $=-89.0244+$ 0.66209 Age, $F(1,19)=22.16, p=.0002$. Inserting the mean younger driver PMCT of $-45.5 \mathrm{~dB}$ into that equation and solving for Age yields 65.7 years as the best estimate of the age at which PMCT begins to decline (assuming a linear trend).

Correlations of PMCT, age, UFOV®, and simulator measures are shown in Table 1.

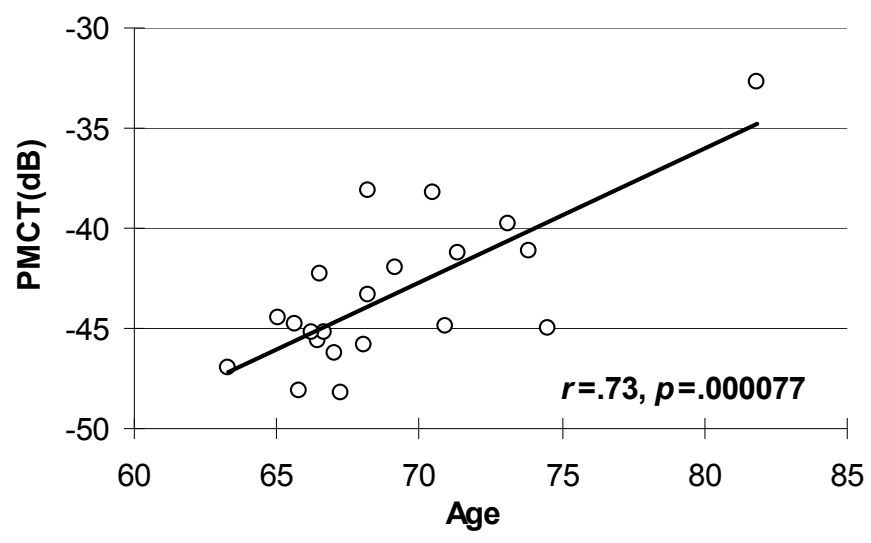

Figure 1. PMCT by Age

Table 1. Pearson Product Moment Correlations Between Visual Function Measures, Age, and Simulator Performance $(N=21)$

\begin{tabular}{lccccc}
\hline & PMCT & Age & Crash & Missed Stop & G2-rater \\
\hline PMCT & 1 & $.73^{* * *}$ & $.63^{* * *}$ & $.53^{* *}$ & $.66^{* * *}$ \\
Age & $.73^{* * *}$ & 1 & .33 & .12 & $.40^{*}$ \\
UFOV1 & .09 & -.1 & .16 & $.54 * *$ & -.05 \\
UFOV2 & $.74 * * *$ & $.48^{*}$ & $.72^{* * *}$ & $.71^{* * *}$ & $.58^{* *}$ \\
UFOV3 & $.50^{* *}$ & $.44 *$ & $.45^{*}$ & $.54 * *$ & .29 \\
\hline$p<.05, * * p<.01, * * *$ & $p<.001$, all tests are directional (ie., 1-tailed) &
\end{tabular}

PMCT was very strongly associated with UFOV2, suggesting that the two vision measures tap common or overlapping visual functions, as Henderson et al (2007) had suggested. PMCT was very strongly associated with crashes and with drivers' overall assessed simulator performance (G2-rater), and strongly with Missed Stops. Age was very strongly correlated with PMCT, and moderately with UFOV2 (divided attention), UFOV3 (selective attention), and G2-rater.

Figures 2 through 5 show regression lines for some relations of interest listed in Table 1.

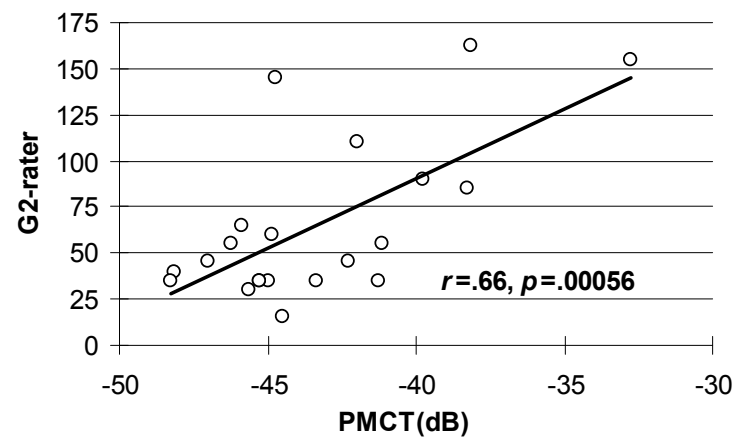

Figure 2. Simulator Score by PMCT

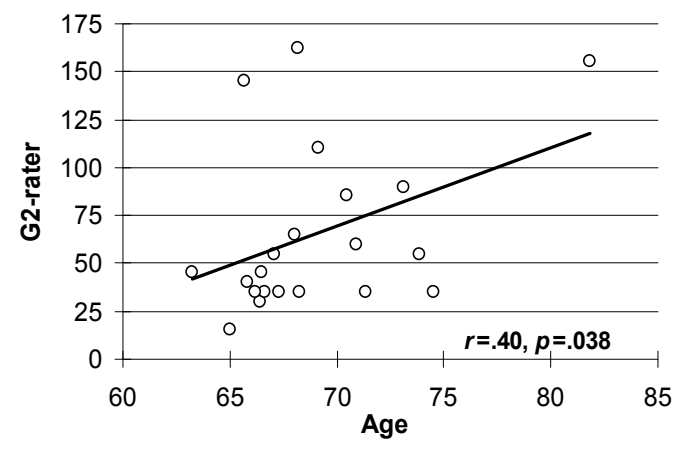

Figure 3. Simulator Score by Age 


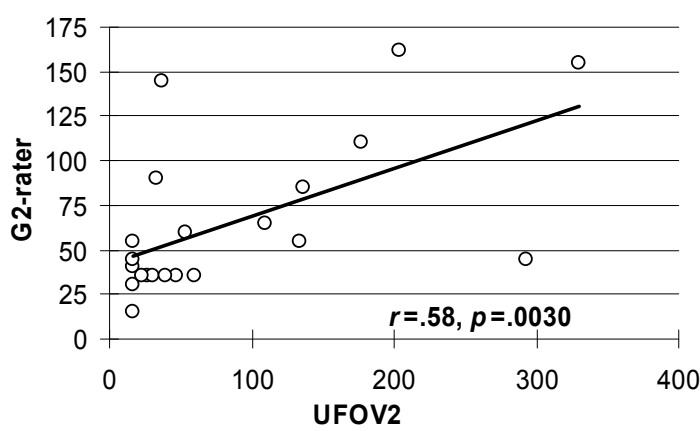

Figure 4. Simulator Score by UFOV2

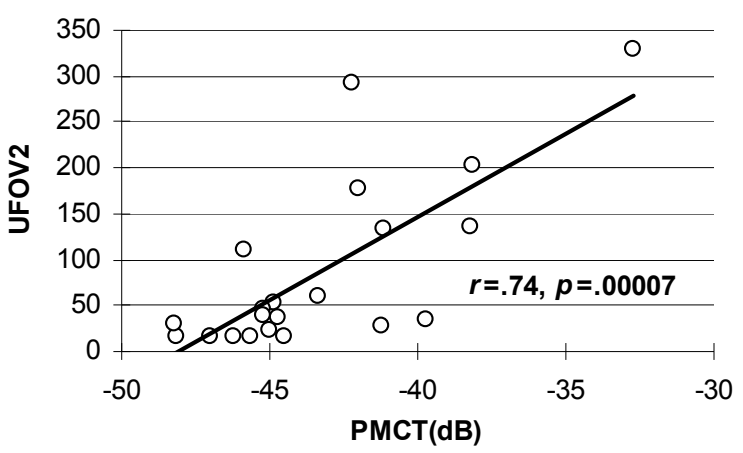

Figure 5. UFOV2 by PMCT

Table 2 shows partial correlations of vision measures on driving simulator performance, holding single independent variables constant, to assess age mediation of vision measures to driving performance, and to determine if UFOV2 and PMCT are measuring the same visual function.

Table 2. Partial Correlations Between Selected Variables $(N=21)$

\begin{tabular}{cccccc}
\hline Age constant & UFOV2 & UFOV3 & Crash & Missed Stop & G2-rater \\
\hline PMCT & $.650^{* * *}$ & .295 & $.599^{* *}$ & $.661^{* * *}$ & $.593^{* *}$ \\
UFOV2 & 1 & $.558^{* *}$ & $.673^{* * *}$ & $.748^{* * *}$ & $.484^{*}$ \\
\hline PMCT constant & Age & UFOV3 & Crash & Missed Stop & G2-rater \\
\hline UFOV2 & -.133 & $.479 *$ & $.482^{*}$ & $.553^{* *}$ & .183 \\
UFOV3 & $.479 *$ & 1 & .192 & .366 & -.061 \\
\hline UFOV2 constant & Age & PMCT & Crash & Missed Stop & G2-rater \\
\hline PMCT & $.641^{* *}$ & 1 & .212 & .024 & $.424 *$ \\
UFOV3 & .193 & .047 & -.040 & .139 & -.136 \\
\hline$*<.05, * * p<.01, * * * p<.001$, all tests are directional (ie., 1-tailed) &
\end{tabular}

Table 1 shows high correlations $(p<.001)$ of PMCT and UFOV2 with G2-rater. In comparison, Table 2 shows that controlling for age, both PMCT and UFOV2 were significantly related to G2rater $(p<.01$ and $p<.05$ respectively). Thus, within this group of older drivers, Age mediates some of the associations between the vision measures and simulator performance (G2-rater). Correlations of PMCT and UFOV2 with Crash and Missed Stop remain high when Age is held constant, indicating that Age does not substantially mediate the high correlations between those variables.

Controlling for PMCT, UFOV2 was unrelated to G2-rater, but was related (with lower significance) to Crash and Missed Stop, indicating that PMCT accounted for all the variance in G2-rater explained by UFOV2, and some of the variance in Crash and Missed Stop explained by UFOV2. Controlling for UFOV2, PMCT was not significantly related to Crash or Missed Stop, indicating that PMCT does not account for any additional variance over UFOV2.

Controlling for UFOV2, PMCT was moderately related to G2-rater. Therefore, as PMCT mediates the correlation between UFOV2 and G2-rater, PMCT may capture a component of driving-critical visual function that UFOV2 does not, perhaps associated with bottom-up scanpath generation (Henderson \& Donderi, 2005). 
Controlling for either UFOV2 or PMCT, UFOV3 was unrelated to any simulator performance measure.

\section{DISCUSSION}

For the first time, PMCT has been directly validated as an accident risk predictor using older drivers' driving performance in a driving simulator. In addition, PMCT has again been validated against UFOV® measures, which have been the only visual function measures to be validated repeatedly against both simulator performance and (retrospective and prospective) accident records.

Asking participants to detect a grating stimulus (ie., method of limits) gives as valid a measure of peripheral motion contrast threshold as the previously reported two-alternative forced choice procedure, although yes-no detection procedures are widely held to be more vulnerable to response criterion effects, particularly regarding interactions with age. Specifically, older participants are generally found to be more conservative responders, which confounds response criteria and sensitivity. The absence of that issue here, shows that the increased practicability of the new PMCT assessment procedure (which requires under 10 minutes to administer) is not at the expense of its validity as an important visual function measure. That is, bias does not obscure the individual PMCT differences important for identifying at-risk drivers.

Older drivers are poor at assessing their visual functions and detecting gradual visual losses occurring over time, but when informed of a functional PMCT deficit, they may adopt compensatory strategies for age-related visual and driving deficits (Holland, 1993; Slzyk, Seiple, \&Viana, 1995; Stalvey \& Owsley, 2000). For example, at-risk drivers could restrict the length of their glances away from the driving environment to well under two seconds (Henderson et al, 2007). In addition, research could determine if training in voluntary scanning techniques (Scheiber, 1998) offers an effective countermeasure for the deficit.

Our anticipated revisions will shorten the PMCT assessment methodology, making the PMCT test practical and usable for driving examiners, and for medical practitioners expected to pronounce on the driving safety of their referrals.

\section{ACKNOWLEDGEMENTS}

This study has received approval from the University of Ottawa Ethic's review committee and was conducted in compliance with the regulations to govern research on human participants. This study was financially supported by an Ontario Neurotrauma Foundation grant and a National Sciences and Engineering Research Council grant to Dr. Sylvain Gagnon, and by a National Sciences and Engineering Research Council grant to Dr. Charles Collin.

\section{REFERENCES}

Ball, K., Roenker, D. L., Wadley, V. G., Edwards, J. D., Roth, D. L., McGwin, G., et al. (2006). Can High-Risk Older Drivers Be Identified Through Performance-Based Measures in a Department of Motor Vehicles Settings? The American Geriatrics Society, 54, 77-84. 
Bédard, M., Porter, M., Marshall, S., Isherwood, I., Riendeau, J., Weaver, B., Tuokko, H, Molnar, F., \& Miller-Polgar, J. (2008). The combination of two training approaches to improve older adults' driving safety. Traffic Injury Prevention, 9, 70-76.

General Accounting Office. (2007). Older driver safety: Knowledge sharing should help states prepare for increase in older driver population. (Report to the Special Committee on Aging, U.S. Senate, April 2007) GAO-07-413.

Henderson, A.S. \& Donderi, D.C. (2005). Peripheral motion contrast sensitivity and older drivers' detection failure accident risk. In Proceedings of the Third International Driving Symposium on Human Factors in Driver Assessment, Training and Vehicle Design, 41-50, Rockport, Maine 2005.

Henderson, A.S, Gagnon, S., Bélanger, A., Tabone, R., \& Collin, C. (2007). Near peripheral motion detection threshold predicts detection failure accident risk in younger and older drivers. In Proceedings of the Fourth International Driving Symposium on Human Factors in Driver Assessment, Training and Vehicle Design, 191-198, Stevenson, Washington 2007.

Holland, C.A. (1993). Self-bias in older drivers' judgements of accident likelihood. Accident Analysis and Prevention, 25(4), 431-441.

Landy, F.J. (1992). Alternatives to chronological age in determining standards of suitability for public safety jobs. Volume I: Technical report. University Park, PA: Center for Applied Behavioral Sciences.

Li, G., Braver, E., \& Chen, L. (2003). Fragility versus excessive crash involvement as determinants of high death rates per vehicle-mile of travel among older drivers. Accident Analyses \& Prevention, 35, 227-235.

Massie, D.L., Campbell, K.L., \& Williams, A.F. (1995). Traffic accident involvement rates by driver age and gender. Accident Analysis and Prevention, 27(1), 73-87.

National Highway Traffic Safety Administration (2001). Traffic Safety Facts 2000: Older Population. DOT HS 809328.

Schieber, F. (1998). Recent developments in vision, ageing and driving 1988-1994. Technical Report No. UNMTRI-94-26. Ann Arbor, MI.

Sekuler, R., \& Owsley, C. (1982). The spatial vision of older humans. In R. Sekuler, D. Kline, \& K. Dismukes (Eds.), Aging and Human Visual Function, 185-202. New York: Alan R. Liss.

Szlyk, J.P., Seiple, W., \& Viana, M. (1995). Relative effects of age and compromised vision on driving performance. Human Factors, 37(2), 430-436.

Stalvey, B.T., \& Owsley, C. (2000). Self-Perceptions and Current Practices of High-Risk Older Drivers: Implications for Driver Safety Interventions. Journal of Health Psychology, 5, 441456.

Staplin, L., Lococo, K.H., McKnight, A.J., McKnight, A.S. \& Odenheimer, G.L. (1998). Intersection Negotiation Problems of Older Drivers, Volume II: Background Synthesis on Age and Intersection Driving Difficulties. HS-808 850, Volume II,; Report No. 1446/FR,; Background Synthesis, National Technical Information Service 
Tsang, P.S. (1997). Age and pilot performance. In R.A. Telfer \& P.J. Moore (Eds.), Aviation training: Learners, instruction and organization (pp. 21-40). Brookfield, VT: Avebury.

Yanik, A.J. (1986). What accident data reveal about elderly drivers. SAE Technical Paper \#851688. Warrendale, PA: Society of Automotive Engineers. 